\title{
Treatment of Muscular Hydatidosis of the Limbs about 15 Cases
}

Ayoub Mjidila*, Youness Dahmani, Ismail Kabbaj, R. A. Bassir, M. Boufettal, M. Kharmaz, Mly O. Lamrani, Mr S. Berrada

Department of Traumatology-Orthopedic, Faculty of Medicine and Pharmacy, CHU Ibn Sina of Rabat, Rabat, Morocco

DOI: $\underline{10.36347 / \mathrm{sasjs} .2021 . \mathrm{v} 07 \mathrm{i} 02.010}$

| Received: 18.01.2021 | Accepted: 01.02.2021 | Published: 10.02.2021

*Corresponding author: Ayoub Mjidila

\section{Abstract}

The muscular localization of echinococcus is very rare. most often the diagnosis is made late as the clinical signs are mild and not very suggestive. The diagnosis is based on ultrasound which remains the paraclinical examination of choice and is confirmed by histology. We present a retrospective study of a serie of 15 isolated and primary hydatid cyst cases in peripheral muscles between 2010 and 2020. The diagnosis was made by ultrasound. All of our patients underwent surgical excision of the hydatid cyst associated with anti-helminthic treatment.

Keywords: Hydatid cyst, muscular, ultrasound, surgery.

Copyright $\odot 2021$ The Author(s): This is an open-access article distributed under the terms of the Creative Commons Attribution 4.0 International License (CC BY-NC 4.0) which permits unrestricted use, distribution, and reproduction in any medium for non-commercial use provided the original author and source are credited.

\section{INTRODUCTION}

The muscular localization of hydatid cyst is rare, even in endemic countries [1, 2]. It is a zoonosis caused primarily by the larvae of Echinococcus granulosus, multilocular echinococcosis, echinococcus vogeli, echinococcus oligarthrus [3] common to humans and many mammals.

The aim of this work is to highlight the epidemiological, clinical and above all therapeutic aspects of this condition, based on the study of our cases and the review of the literature.

\section{CASE REPORT}

In this work, 15 cases of muscular hydatidosis treated surgically in our institution were collected over a period of 10 years between 2010 and 2020. The analysis of epidemiological, anamnestic, clinical, ultrasound data and additional examinations allowed us to specify the characteristics of these hydatid locations.

These are 5 men and 10 women. The average age of the patients was 41 years with extremes of 20 to 80 years. All of the patients were from rural areas. The reason for consultation was swelling of the soft tissues gradually increasing size (Fig $1 \& 2$ ).
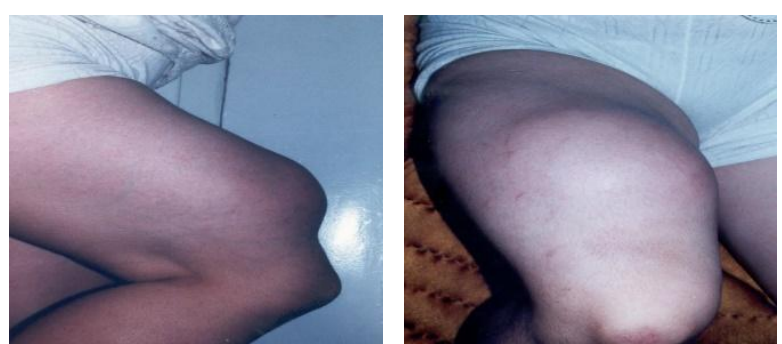

Fig $1 \&$ 2: Tumefaction of the anterior aspect of the right thigh

Systematic ultrasound of the swelling revealed signs in favor of hydatidosis, which were analyzed according to the Gharbi classification [4] as Type III for all patients (Fig-3).

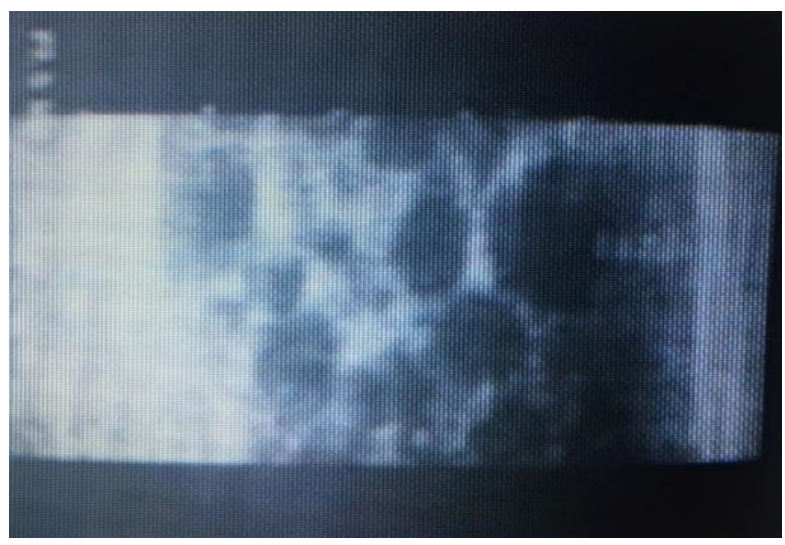

Fig-3: Ultrasound appearance suggestive of hydatid cyst 
The muscle involvement was most often single and primary. The proximal muscles of the lower limbs were most frequently affected.

Biologically, hyper eosinophilia was present in 6 patients, and hydatid serology (indirect immunofluorescence, ELISA) came back positive in $60 \%$ of cases. The extension assessment included a chest x-ray and an abdominopelvic ultrasound. He had not detected any other visceral localization, notably hepatic or pulmonary.

The treatment has always been surgical with pericystectomy associated with anti-helminthic chemotherapy (Fig-4). The early course was favorable. At the 18-month follow-up, no local or distant recurrence was noted.

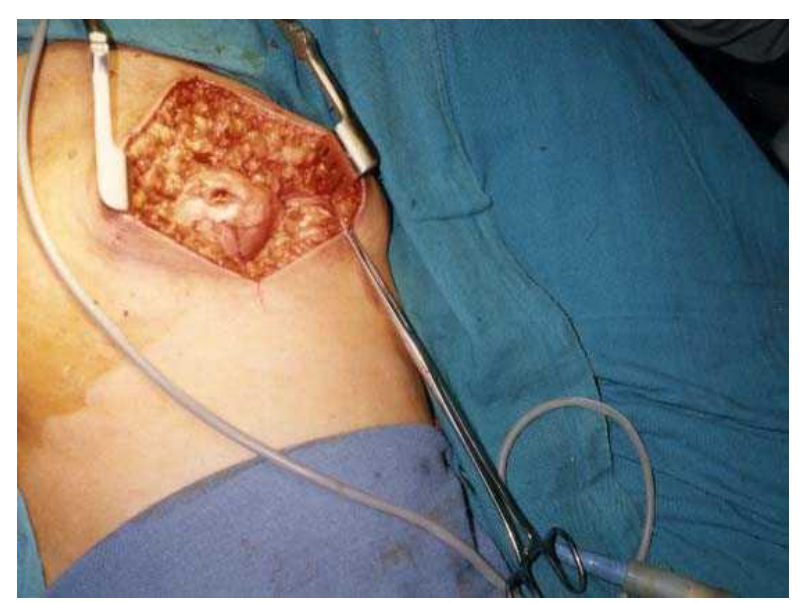

Fig-4: Perikystectomy removing the cyst

\section{DISCUSSION}

The frequency of the muscular forms of hydatidosis is currently decreasing, it is estimated between 1 and 5.4\% of all hydatid localizations [5-7].

Because of its contractility and its production of lactate, the muscle is an unwelcoming environment for the development of the hydatid larva. However, muscular hydatidosis is most often isolated; its association with other hydatid sites has only been reported in $8 \%$ of cases [8].

Clinically, the symptoms of muscular hydatidosis are nonspecific, with an onset that is often inconsistent. It manifests itself by a mass of variable volume, often soft in consistency, well limited and painless, all developing in a context of preservation of general condition. All of our patients had the same clinical description. Sometimes the clinical picture simulates a lipoma, a calcified hematoma, a malignant or benign tumor, or a hot abscess in case of cracking or superinfection, sometimes it can be manifested by signs of nerve compression, or by signs of allergic reactions ranging from a simple rash to anaphylactic shock in case of rupture or puncture of a cyst $[9,10]$.
Biologically; the increase in the concentration of eosinophils is not constant $[11,12]$ and therefore is of interest only in diagnostic orientation. Hydatid serology (immunofluorescence and Elisa) is positive in $50 \%$ of cases $[10,12]$, which is not far from our series. On the other hand, biology finds its place in the event of persistence of a high level of antibodies or a rise in 6 months to 1 year after an intervention suggest a secondary hydatidosis [13].

Ultrasound is of the utmost importance and should be the first-line paraclinical examination. In our series, it made it possible to carry out the preoperative diagnosis in all cases. It is sufficient and reliable in $95 \%$ of cases [14] and can be supplemented by CT if there is any doubt about the ultrasound.

Treatment of a hydatid muscular cyst is primarily surgical. Dissection must be careful to avoid any opening of the cyst and the dissemination of its contents $[9,12]$.

However, hydatidosis is a public health problem in endemic countries. Therefore, the real treatment for echinococcosis remains prophylaxis, which must interfere at all levels of the epidemiological chain [15].

\section{CONCLUSION}

Muscle hydatidosis remains rare. Its diagnosis is mainly ultrasound avoiding the puncture. The treatment is exclusively surgical removing the cyst without breaking it.

\section{Conflict of interests: None.}

\section{REFERENCES}

1. Baldeli F, Papelli R. The biological diagnosis of recidivism. International Hydatidology Symposium. Med Chir Dig. 1989; 18:301-312.

2. Saimot AG. The other sites of hydatidosis. Rev Prat. 1978; 28:2887-2894.

3. Kammerer WS, Schantz PM. Echinococcal disease. Infect Dis Clin North Am, 1993; 7: 60518.

4. Gharbi HA, houssine W, Brauner MW, Dupuch K. Ultra sound examination of the hydatic lover. Radiology, 1981; 139:459-463.

5. Akjouj S, El Kettani N, Raissouni Z, Semlali S, Aziz N, Amil T, Chaouir S, Benameur M. What is your diagnosis? Hydatid cyst of the arm. Journal de radiologie. $2006 \mathrm{Jul} \mathrm{1;87(7-8):989-91.}$

6. Hammami T, Noomane F, Ketata M, Ganneme Y, Nasr M, Zouari K. Muscular hydatid cyst thigh. About three observations. Rev Chir Orthop Reparatrice Appar Mot, 2002; 88:193-196.

7. Guthrie JA, Lawton JO, Chalmers AG. Case report: the hydatid disease MR appearances of primary intramuscular. Clin Radiol, 1996; 51:377379. 
8. Kehila M, Allegue M, Abdessalem M, letaief R, Said R, Khlfllah A, Hamid RRH, Jerbi A. The cysthydatid of the psoas muscle (Report on a case). J Radiol, 1987; 68:265-268.

9. Bourée P, Bisaro F. Hydatidosis: aspects epidemiological and diagnostic. Antibiotics, 2007; 9:237-45.

10. Orhan Z, Kara H, Tuzuner T, Sencan I, Alper M. Primary subcutaneous cyst hydatic disease in proximal thigh: an unusual localisation: a case report. BMC Musculoskelet Disord, 2003; 4:25.

11. Abdel-Khaliq RA, Othman Y. Hydatid cyst of pectoralis major muscle. Case report and note on surgical management of muscle echinococcosis. Acta Chir Scand, 1986; 152:469-71.
12. Durakbasa MO, Kose O, Islam NC, Kilicoglu G. A primary hydatid cyst of the gracilis: a case report. J Orthop Surg. 2007; 15:118-20.

13. Ben Ayaed M, Kamoun N, Makni K, Ben Romdhane K. Hydatid cyst, 281 localized cases unusual, observed over a period of ten years (1972-1981). Medical Tunisia, 1986; 64:389-395.

14. Bonitacino A, Carino R, Caratozzolo M. Ultrasound in hydatidosis. Symposium international conference on hydatidology. Med. Chir. Dig. 1989; 18:301-312.

15. Agoumi A. Precise of medical parasitology. MEDIKA collection International Horizons edition, 2003: 131-14. 